\title{
Educational Application for Special Needs Is a Learning Tool the Way Forward?
}

\author{
Zeenath Reza Khan, Yusra Yakub Ibrahim, Sonia C. Sadhwani and Sharifa Taimur Salum \\ Faculty of Engineering and Information Science, University of Wollongong, Dubai
}

\begin{abstract}
As the 21st century brings in a revolutionary change in the way students study at schools and universities, technology continues to play a crucial role in helping students achieve more conceptual and practical knowledge of topics taught in classrooms. Students with special needs too are now able to study in a general classroom setting, access relevant technologies and use them for higher cognitive development, helping them integrate with their surroundings. However, existing literature shows that though multiple learning tools exist that do enhance learning in special needs students, they either cater to specific areas of development such as Mathematics and English, or that are targeted towards a specified category of studentswith special needs such as autism and cerebral palsy. Furthermore, despite multiple laws and regulations supporting the right to education launched by the UAE (United Arab Emirates) government for special needs students, there seems to exist a need to provide classrooms across the country with educational applications that have a universal approach particularly in the UAE in order to include students with almost any special needs. This paper looks closely at the existing literature and highlights this gap, especially in the UAE and proposes to develop such a tool based on existing learning concepts.
\end{abstract}

Key words: Assistive learning, distance learning, special needs, learning tool, universal learning approach, VARK theory.

\section{Introduction}

Technology is a factor that has become synonymous with human existence. It is the key to success in industries such as medicine, construction, entertainment, business, arts and commerce. As human beings continue to become increasingly dependent on tools and gadgets, academic sectors are also flooded with teaching and learning tools to enhance students' overall experience.

During the early stages of technology-use as an educational tool, research was devoted to how accessible-technology could be used to address the individual needs of students. Software programs were developed primarily for use as teaching aids to promote practice and drill [1], or as enrichment aidsthrough simulations and games. Today, various educationalists see technology as a means to stimulate thinking and act as a delivery system that permits

Corresponding author: Zeenath Reza Khan, Ph.D., instructor/mentor, research fields: community informatics, educational technologies and ICT ethics. students to achieve more than the traditional learning experience, going beyond the classroom and making various forms of e-learning popular in most countries [2]. Electronic learning, or e-learning is generally a method used to teach students who are not physically present in class, or who wish to explore opportunities that are not available inside their classrooms with the promise of creating a learning environment beyond time, place, topic or any other prejudice [3].

The use of technology has also become popular in the area of special needs. Researchers continually find ways to make use of technology to educate students with special needs. There has been an improvement in the lifestyle of those with special needs, with the development of technologies such as hearing aids, automated wheelchairs and multiple features on mobile devices such as font enlargement and so on [4].

Only a handful of innovative technologies meet the increasing demand for educative technologies for students with special needs. With the growing popularity of different technologies, including 
information and communication technologies such as computers, mobile phones, recording devices, touch screens and so on, it is no surprise that they have also become commonplace in the field of special education.

Differentiation in the use of technology existed since 1970s with the invention of hearing aids and Braille [5], which was heavily dependent on exceptionality. To open up exciting possibilities for study, the understanding of use of assistive technologies for students with special needs transformed significantly since its early stages. As a tool of differentiation, technology permitted students with different levels of skills to work in their own preferred style and level of readiness [5]. For example, the use of Internet as a research tool enables students to come across a wide range of resources. Teachers may provide guidance to students with difficulties toward specific resources that fit the topic at hand while the other students who have the capability to think abstractly search for their topics independently either in classrooms or from home, libraries, cafes and so on (e-learning) [5]. This type of learning tool has further helped offer opportunities for special needs students to overcome certain physical impairments such as hearing, sight, and so on [4].

Existing technologies, however, do not necessarily cater to all people with special needs. There seems to be an urgent requirement for effective and simple solutions that cater to the special needs population at large.

This research highlights the gap in the existing literature and market for such assistive learning tools for special needs students; a tool can be developed on the basis of existing educational theories such as VARK (visual, aural, reading, and kinesthetic learning) and UDL (universal design for learning) in order to enhance special needs students' chances of learning at their pace, using the best-suited learning environment for them.

\section{Technology and Special Needs}

Technology today plays a vital part of people's lives, at home and at work. Students in primary schools are given tools such as tablets to allow more usage of technology and incorporate e-learning. This change in teaching methods has been evolving from West to East, from United States of America to United Arab Emirates, and students have become very comfortable with the addition of technology in their school curricula, that is in fact in keeping with the level of use of technology outside classrooms. It is no shock then that even students with special needs are now expected to be able to use various technologies, which, if integrated into their learning environment, can in fact help them integrate with their socio-environment more easily.

The United States of America was one of the earliest nations to pass a law known as the Individuals with Disabilities Act that requires schools across the country to provide special needs students with the latest technology, in order to support their learning process and help them make the most of what they learn [6]. A method of Individual Education Plan was developed that keeps in mind students' unique learning requirements, and the technologies best suited to them [6]. Research highlights that it is essential to have parental involvement with the inclusion of technology into a special student's curricula [6]. Studies show that if technology is used both in school with teachers, and at home with parents, a student is able to perform better, improve his/her cognitive development and gain more comfort in using new devices and tools [6]. Parents, too, experience its benefits as they are better able to monitor their child's progress and be more involved in their learning activities [6].

Thousand and Villa [7] have described scenarios where schools in the United States accept students across multiple levels of cognitive special needs, and how they are included into classrooms with students that may not have special needs. This process of inclusion makes use of tools to support the student's 
unique needs during his/her schooling while allowing them to be in a general classroom environment. There are multiple characteristics described by Thousand and Villa [7] such as:

- bringing in new technology and methods suited for inclusion;

- encouraging parents to be more proactive in assisting their children;

- creating a sense of acceptance in the minds of the children with special needs and;

- providing each student with the same set of year-end goals to be achieved;

- that help make inclusive education a success.

Abbott [8] identified three key groups of students that can effectively utilize technology and become more inclusive:

(1) The first group makes use of technology to repeat activities, which over time becomes monotonous and is not as effective since it takes place of the primary teacher;

(2) The second group makes use of technology in order to assist learning, where a student uses a tool or device in place of his/her special need. This is more effective as the student is made familiar with tools, but this pertains mostly to those with physical disabilities and not cognitive;

(3) The final group makes use of technology "to enable learning". This group does not give primary focus to technology but to the environment the student learns in along with his/her teachers, specialists and parents, who help the student using the tool fit in this group. An example proposes an application where students are asked questions and need to select an answer back in response.

Abbott [8] argues that this group is making the most effective use of technology and has seen the most positive response in cognitive development of students, resulting in them being more independent and a vital part of society.

\subsection{Brief History of Special Needs Technology}

In the early 1980's, computer technology for students with learning disabilities consisted mainly of instructions commonly referred to as CAI (computer-assisted instruction) [9]. These instructions were generally composed of practice lessons to enhance specific skills. Educators and researchers put CAI into practice to deliver individualized instructions to students with learning disabilities. Computers that were used in this capacity were seen to play the role of the tutor. This role emerged as the computer was distinguished as an extremely effective medium for providing different levels of academic instructions that allowed students to work at their own pace, skill level and provided them with immediate feedback. In addition to tutorial software, drill practice supplied students with many opportunities to practice a skill that has been taught [9].

Over time as classroom instructions began to gain popularity among classrooms, researchers looked into a new dimension of CAI. Researchers began to look at instructional design parameters for effective learning for students with learning disabilities. Researchers in the early 1990's developed computer assisted instructions that were able to engage the student through hypermedia [10, 11]. Research in Ref. [11] suggests that the use of hypermedia study guided and enhanced information retention oflearners who were identified as learning disabled or students' receiving remedial services. The results showed that the hypermedia study guides were feasible educational tools. Boone and Higgins [11] also conducted a three year school-based research study that investigated the use of hypermedia support and basal readers. The results of this study confirmed the effectiveness of using hypermedia software in the general education system. Although the number of studies in the field of hypermedia-based learning itself is relatively small and could benefit from further investigation, benefits of hypermedia and its usage by students with learning disabilities were registered in primary, secondary and higher levels of school classes aplenty [10-14]. 
In the late 1980's and early 1990's as technology advancements began, researchers working in the field of learning disabilities began to investigate the use of multimedia and the power of graphics in special education. Multimedia is a collaboration of video, pictures, sound and graphics that help supply a diverse learning instruction [15]. Studies propose that the use of multimedia enables the student to participate more in their learning process. With the development of technology, multimedia became computer-based, resulting in a shift from a receptive mode to a more interactive mode. Daiute and Morse [16] suggested that students' writing success could be achieved through the power of multimedia. They further suggested that multimedia was one way teachers could assist their students to voice their specific perspectives.

Technology has evolved from providing instructions to supplying support for the completion of tasks and processes. Word processors, word predication, speech recognition, spell check, text-to-speech software, graphic organizers, and online resources have all supported students who have learning disabilities, providing opportunities to enhance their academic weaknesses and complete the required learning objectives with the hope that academic growth will be ensured.

In the year 2011, the Disabled Resources Centre in Long Beach, U.S.A., held a workshop based on issues faced by those with special needs with regards to using a phone, highlighting issues such as the size of phone buttons as well as hearing and processing issues [17]. Those who faced these issues were then provided with phones that eradicated these potential issues. Not only did technology aid those individuals to be more involved with the society, but it also gave average visitors a chance to experience the level of difficulty faced by those with special needs in day-to-day tasks.

Lubinskis [18] highlighted the usage of technology such as iPads to reinforce learning with special needs students. Research suggested that many students tended to shy away from communicating with others, and the usage of various applications on the iPad allowed the students to do tasks such as count coins, where they did not feel intimidated by someone else's presence. Research has also shown that a growth in student functional and social skills occurs which acts as a positive reinforcement, further helping their inclusion into society and everyday life [18]. Researchers suggest that features of applications like readers, font enlargement, brightness adjustment and color-coded timers which have aided students across various levels of special needs have encouraged them to participate further in activities [18]. This form of e-inclusion has also benefitted students who find it difficult to get admission in schools such that parents can homeschool them using some of these applications [19].

In early 2001, the Australian government launched a \$3.5 million initiative to enable special needs students in schools and universities to use relevant technology [20]. One of the ways that was achieved was by providing schools and universities with tablets, which enabled students to overcome issues such as typing on a small keyboard [20]. Certain websites exist such as Setbc.org and Spedclass.com that not only provide classroom resources for teachers and games for students, but also give research reports and feedback on the new emerging technologies for students with special needs and how they may compare with using no technology to assist students [21].

Quenneville [22] has listed various tools that enable inclusion of special needs students within regular classrooms. An example includes word processors like "Write Out Loud" which come with a tool for editing pronunciations to make it sound less synthesized [22]. Another tool called a "Pre-writing organizer" enables students to tackle the issue of brainstorming their ideas through writing, and instead gives them a platform to graphically represent their ideas through drawings, which saves their time [22]. 
Alper et al. [23] have provided multiple instances of interactive technologies being used across the world to educated students with different needs. One of the instances is the usage of a tool called "Uncommon Sense", which provides audio, visual or sensory feedback through the use of the tool by the student, who interacts with the tool orally, through movement or actions. The feedback from the use of these tools have been positive, where students learn to wait in line to play, interact with their fellow students and also have an increased attention span. This tool was primarily tested in a school for autistic students, and shows how small tools can have such a massive impact on autistic student inclusion. These tools not only aid inclusion but give students the ability to learn behavioral aspects which essentially would help them become better members in society [23].

2.1.1 Assistive Technology and Mental Retardation

The use of assistive devices as a method of introducing avenues of communication for people with mental retardation has been gaining popularity in recent years. Means of communication such as the output communication aids that are used to create digitized or synthetic speech have been successfully used by students with autism and related disabilities [24]. Although in the field of education it has been regarded as controversial, the use of keyboards or alphabet boards, facilitated communication, have been utilized as a means of communication.

Individuals with mental retardation have relied heavily on the use of adaptive devices and technologies for access. Prior to the Education of All Handicapped Children Act [25-27], and the de-institutionalization of individuals with mental retardation in the 1980s, most of the devices used by these individuals were considered as "low tech". Low tech devices are passive, simple and have few moving parts such as adaptive switches, communication boards, cell systems, adaptive books, tactile enhancement, etc.

Public Law 94-142 (Education of All Handicapped
Children Act) and deinstitutionalization have brought focus on people with mental retardation in community and public schools by mandating a free and appropriate education. To meet the educational needs of these students, the focus on technology has transferred from "low-tech" to "high-tech" devices. High tech devices are described as more complex; usually integrated sophisticated electronic components including alternative and augmentative communication devices, modified or alternative keyboards, Braille printers and text-to-speech devices and computers for educational purposes [27-29].

Research shows that technology as a teaching tool instantaneously had an impact on the education of individuals with mental retardation. In 1998, Wehmeyer [30] suggested that the use of assistive technology devices was increased independence, integration skill and self-determination. Even though many of the "low tech" and "high tech" assistive technology devices had significantly increased access to the education environment for individuals with mental disabilities, the introduction of supporting software and technology was regarded as the greatest agent of change not only to the curriculum but also to the way it is being taught [30].

Technology is currently being used to help individuals with mental retardation present work in the classroom. With the help of assistive technology, students with moderate and severe disabilities construct alternative portfolios of their work. Through making use of adaptive tools such as IntelliKeys keyboards and Overlay Maker, these students are able to build portfolios of their annual work. These tools have enabled these students with mental retardation to generate products identical to their non-disabled peers [31].

2.1.2 Assistive Technology and Hearing Impaired Another area of special needs that has benefitted from the traditional use of technology is hearing impaired. However with the advances in technology, it also provided challenges for individuals with hearing 
loss as computers were an inherently auditory-visual media. Even though this visual component permitted presenting visual communication, literature has focused on instruction that has dealt with the development and use of technology to work with or around hearing loss. Corbett and Micheaux [32] identified several residential schools for the deaf that spent significant amount of money on hardware, software and connections for instructional technology to improve educational and social programs.

Real-time captioning technology was originally intended to provide a visual process for printing to assist in language acquisition [33] and has since moved to live-lectures and news. Now, technology exists that have decoders built into TVs and movies which are close-captioned for the purpose of education [34]. This has opened educational avenues in schools to curricula previously closed to individuals with hearing loss [35].

\subsection{Issues with Existing Assistive Technologies and Special Needs}

Studies show that the use of assistive technology for mental disability, among other special needs, does not lie in the introduction and development of new technology but rather in full and accurate implementation of existing technologies. The Arc (The Association for Retarded Citizens), a national advocacy organization that speaks on behalf of individuals and their families suffering from mental retardation, has frequently expressed concerns about access to technology for these individuals. Wehmeyer [36] states, "It appears that, for a variety of reasons, assistive technology devices remain largely underutilized by people with mental retardation".

A number of issues have been identified by researchers that highlight the existing underutilization of assistive devices. These include:

- the cost of purchasing equipment [27, 36, 37];

- the abandonment of technology [27];

- the lack of information about the technologies and what they are available for [30];

- the recognition of appropriate technology features [27];

- deficiency in assistive learning tools that could be used by individuals with mild to severe cognitive disabilities [36];

- the development of devices that are too complex $[36,38]$.

Among other issues, Spangenberg [39] suggests factors that bar students with special needs from doing well in their university life. Sites such as Moodle and Blackboard which are used by professors to encourage discussions and post updates are not easy to navigate through and their small icons and poor user interface are difficult to use by those with special needs [39]. Since those with special needs also pay the same amount of fee and are not able to effectively use such technology, research suggests a very wide gap that demands to be filled with the increasing number of special needs students enrolling in university.

Multiple key stakeholders have been identified in the research, out of which one of them is a teacher. The teacher facilitates e-inclusion in a classroom environment, and thus has a rather large impact on a student's learning process. Williams [40] suggests that teachers face tremendous pressure with poor technology provisions provided by the school. This issue may be resolved by providing teachers with required websites, aids and other relevant resources, as these teachers already are handling a big responsibility and need to update students with new tools regularly. Since the education sector requires proof in terms of report cards and results of that manner, the teachers find it essential that these tools come with scores, since the education sector promotes students on basis of his/her result. This result should also be shown to the parents of the student in order to help them understand how their child is doing academically. Very few, if at all, tools provide such reporting facility that track student progress.

Okolo and Ropke [41] take up key issues that occur 
in regards to inclusion of those with special learning needs. Taking the example of students in year 12, the researchers mention how they differ from their average classmates due to time they take to read and write [41]. Being able to solve questions and explain how they manage to do so is also a skill that needs attention in early years, as it is not an easy skill to develop [41]. Okolo and Ropke [41] also mention gaps in terms of websites online, which may not be special needs friendly, and the information that is often too complex and short for students to fully grasp. Researchers suggest strengthening basic skills such as reading with applications on the web, tablets and computers that should be used effectively and should be relevant to their needs [41].

Studies also suggest that a sense of individuality is hard to identify when using technology to assist students [21]. For instance, students have different behavioral patterns and responses, and may react differently than others in their work groups, and this factor is often due to them being from various cultures, ethnic backgrounds, races and gender. Researchers [21] suggest that there is a requirement of a "one size fits all" kind of tool that would cater to students despite their differences. Once the tool has been developed that caters to this UDL (universal design for learning) approach, it has to be priced in a way that is easy to obtain by schools and parents, which again is a massive issue. Upon deployment of these tools, researchers should make it a point to evaluate the tool based on the students' interaction and response, and not traditional technology related ground rules established by governing bodies like IEEE (Institute of Electrical and Electronic Engineering). Continuous modifications and additions should be made to enable the tool to assist these students in real life based scenarios.

Courtad and Bouck [42] highlight tools used in multiple areas of learning, like mathematics, reading and writing. Researchers also suggest however that a tool that falls under this conceptual framework may not necessarily cater to the uniqueness of the students being taught and may not be sustainable to every student, but maybe a selected few [42].

Overall, research suggests that although new technologies are attempting to cater to special needs students' learning needs, there still exists a need for a learning tool that not only uses UDL but more accepted and tested learning theories that cater to individual special needs students.

\section{UAE and Special needs}

The UAE is a federation of seven emirates that came together in 1971 to form a nation. It is a Muslim country that follows the Muslim code of law called the Shari'ah derived from the Holy book, the Qur'an. The country's population stands at approximately 5.4 million with over $80 \%$ expatriate community residing in the country.

The UAE is one of the fastest growing economies in the world, a hub for business, trade, tourism and a hotspot for culture and tradition. Its remarkable developments, include:

- the Ferrrai World in Abu Dhabi;

- Burj Khalifa the tallest residential tower in the world in Dubai;

- a metro built into an existing metropolitan city in Dubai;

- Masdar sustainable city in Abu Dhabi.

And many more achievements and success stories of integration, value and security have made it the Expo 2020 host country as well. The UAE government pays special attention to technology-use and has many successful e-government ventures, e-learning ventures and e-tourism ventures that are highly commended and sought by the rest of the world.

In the UAE, most schools have computer laboratories with library databases, and smart boards in their classrooms so that they experience technology-enabled learning. This is primarily done to enhance their experience as well as keep them up to 
date with latest developments in their field of interest.

However, the same is not yet true for all schools supporting special needs students.

\subsection{Laws Pertaining to Special Needs Students in the $U A E$}

Prior to 2006, private schools in the UAE were permitted to accept or deny special needs students for any reason they deemed fit [43]. However, the Federal Law 29 pertaining to the Rights of Individuals with Special Needs aims to tackle the discriminatory concerns against individuals with special needs, promoting equality and fairness in education, employment, health care and sports opportunities [43].

The introduction of Law 29 was inspired by the 2006 United Nations Convention on the Rights of Persons with Disabilities [43]. The former was aimed at motivating governments to take necessary measures to provide equal opportunities to individuals with special needs [43].

Law 29 incorporates a wide spectrum of special needs including those with temporary or permanent inabilities in one or more of the following areas: communication, mental, sensory, educational, physical, or psychological capacity [43].

In March of 2014, a new law was issued by His Highness Sheikh Mohammed bin Rashid Al Maktoum, the Vice President and Prime Minister of the UAE to compliment Law 29. It seeks to "protect the rights of people with disabilities in the emirate of Dubai" [44]. It advocates the involvement of special needs people into the society, particularly in the education field [44] through increased community awareness.

\subsection{Importance of Technology for Special Needs in the $U A E$}

Dyes [45] identified the important role that technology plays towards integrating individuals with special needs and the society within the UAE suggesting that technology has radically changed the lives of UAE residents with special needs by providing them the opportunity to be educated, and develop professionally.

Initiatives such as the ICDL (International Computer Driving Licence) certification program for assisting the visually impaired, was set up in Abu Dhabi at the ICDL training and testing centre to encourage special needs persons, irrespective of their age, to use technologies to help them obtain the education and training levels needed to be included in the workplace [45].

The ICDL GCC foundation also set up the "IT Skills for All" initiative within the UAE to ensure the inclusion of individuals with special needs in to the community [45]. The above mentioned initiative tried to motivate private and public sectors to greatly increase their efforts of increasing the number of technological facilities for individuals with special needs. The criterions set for such facilities included no physical barriers that restrict physically challenged individuals. The main objective of IT Skills for All was to simplify the learning process and make it an interactive experience [45].

In 2012, ZU (Zayed University) office of accessibility for special needs students achieved a milestone with the inauguration of the Khalaf $\mathrm{Al}$ Habtoor Assistive Technology Resource Centre [46]. The recently introduced technology centre was worth one AED 1 million, providing the campus with technologies that enhanced and simplified the learning experience of students with special needs enrolled in ZU [46].

Furthermore, the rapid pace of technology has played an important role in providing assistive learning to individuals with special needs in the country. UAE's Ministry of Education signed a MOU (Memorandum of Understanding) with Samsung with the aim of providing educational technologies to children with special needs [47]. The MOU was signed as part of the GESS (Gulf Education Supplies and Solutions) Exhibition, held at Dubai World Trade Centre, by the UAE Minister of Education, His 
Excellency Humaid Mohammad Al Qatami, and the president of Samsung Gulf Electronics, Mr. Young Soo Kim [47].

The first phase of the MOU between Samsung Hope for Children and the Ministry of Education will be implemented soon, granting Samsung GALALXY Note 10.1 devices and ATIV Smart PCs for all special needs students enrolled in Grades 1-3 as well as their teachers for all public schools across the country [47]. These devices are intended to be used by the teachers as part of their regular curriculum, increasing the interactivity levels within classrooms. The second phase of this memorandum involves developing digital content which incorporates the schools' educational curriculums and maximize the power of technology which has not yet been implemented.

Other initiatives include the Doris-Duan Young Healthcare City-based facility that aims to provide specialized, in-home educational services for autistic adults who are 16 years and above [48]. The facility has the capacity to cater for up to 60 students providing them with a team of well-educated and trained professionals. The professionals are expected to apply behavioral analysis to help minimize the challenges posed by Autism and other developmental disorders [48].

Hana Al Hamdani, Head of Technical Committee and Special Needs at ADEC (Abu Dhabi Education Council), announced ADEC's efforts in aiming to provide students with special needs equal opportunities to help them develop and shine through their abilities and talents [48]. In 201450 diverse types of devices will be made available for students with special needs and around AED 3 million will be sponsored by ADEC to acquire new modern devices for other categories in special needs [48].

ADEC is well known for integrating about 11,775 students with special needs into a number of different schools in Abu Dhabi, the capital city of UAE [48]. In 2014 alone, ADEC managed to integrate 4,558 students and plans to further integrate 68 more special needs students from various special needs institutes including ZHO (Zayed Higher Organization) for Humanitarian Care and Special Needs [48].

Al Jalila Foundation was established by His Highness Sheikh Mohammad Bin Rashid Al Maktoum in 2012, to train and educate teachers inassisting in the process of inclusion of students with special needs [49]. The professional training of teachers involves classroom-based practical sessions and mentoring phases. The Jalila Foundation targets to train about 130 teachers from 20 schools in its first phase [49].

The extension of Jalila Foundation, the Ta'alouf (Harmony) program involves training for parents of children with special needs. During its first batch, 53 parents proudly graduated, and in February 2014, the second batch of the training program was expanded to include 100 parents. Over the next three years, the Ta'alouf program aims to graduate $400-800$ parents from its program [49].

\subsection{Government Recognition of Efforts towards Special Needs Education}

In 2009 His Highness Sheikh Mohammed bin Rashid Al Maktoum appointed HRH (Her Royal Highness) Princess Haya Bint $\mathrm{Al}$ Hussein as the chairperson of INDEMAJ, a nonprofit organization promoting education for all UAE children including those with special needs [50]. INDEMAJ aims to minimize, if not eradicate, the gap that exists in the special needs students' skill levels through the use of state of the art tools and technologies [51]. The Resource and Development Centers of INDEMAJ are fully equipped with high quality technologies and educational resources that provide all students with an opportunity to get involved in an interactive learning process [51].

To further promote creative and innovative ideas towards educating and training individuals with special needs, HRH Princess Haya Bint Al Hussein awards those who have significantly contributed with 
initiatives to increase awareness actions for the special needs sector [52]. The award aims to increase awareness and promote the growth of best practices in terms of educating and rehabilitating individuals with special needs. Furthermore, it aims to create a future environment that is creative and capable of providing breakthrough services for individuals with special needs [52].

\section{The Gap}

Despite such initiatives, awards and laws in the UAE, of the over 100 schools that are either exclusively special needs schools or inclusive school systems (Gulf News, 2014), very few actually use any assistive application that has been developed based on educational theories to cater specifically to special needs students' learning, enhance their educational environment in order to integrate them into their surroundings. Many of these schools use assistive technologies, specifically devices that help specific needs such as hearing loss, sight impaired, and so on. But, there seems to be limited or no literature that provides research into assistive applications developed for special needs students, regardless of their disability, that can be used by teachers to not only help special students learn, but to track their progress in order to help develop learning programs that can better suit individual students as well.

Based on the review of existing literature there still remain some glaring drawbacks in the current educational tools as summarized by Jain et al. [4]:

- Individuals growing up with disabilities are unable to use mouse, keyboard normally. They need some technology to make their work easy without using these devices such as software that allow for interaction through touch screens;

- Person suffering from blind or low vision problem are unable to view contents on screen easily due to small screen resolution;

- Special training is needed for instructors to teach students having such disabilities;
Users using hearing aids experience disturbance from digital mobile phones, while people who have physical impairments may find it hard to hold and activate the buttons on mobile devices.

\section{Conclusions}

An interactive environment combined with the appropriate technology can radically transform the lives of individuals with special needs allowing them to explore the world and the opportunities it provides them [45]. Modern technology encourages special individuals to be more creative, get involved in discussions, improve their problem solving skills, allow for flexible thinking and promote risk taking, all of which contribute in the cognitive development as well as promote personal and professional growth of individuals with special needs [45].

Review of existing literature has highlighted the varying number of existing assistive technologies that already exist worldwide for schools and teachers to help aid in integrating special needs students through improved learning. Research has put forward facts that demonstrate how assistive technology has in fact proven to be beneficial tospecial students and provide them with a way of being included in their surroundings, as well as aiding overall development.

However, it is strongly believed that this paper has highlighted the existence of a gap that prevails in the market due to the availability of specific solutions that have been developed to cater towards limited needs, specifically assistive technologies that are more hardware than software. A requirement for a more generalized solution is needed to encourage more usage of technology as well as help special students retain key information that can be carried on once the student completes his/her education.

The solution possibly is a learning aid that should be developed that will provide key skills based on existing and accepted learning theories, which can help potential students learn life-skills, and integrate with their surroundings with ease. 


\section{Acknowledgement}

The authors would like to thank the University of Wollongong in Dubai's Faculty of Engineering and Information Science for the facilities and resources required to complete this research project. To Dr. Catherine Todd, Associate Professor at UOWD, Dr. Mohamed Salem, Professor and Acting President at UOWD, and Dr. Farhad Oroumchian, Associate Professor at UOWD for their continued guidance and support. To Rashid Paediatric Therapy Centre, Dubai for providing crucial information to understand the field of special needs, requirements, specifications and to provide access to their teachers and students for the same. Last but not least, to the families of the authors.

\section{References}

[1] Saskatoon Public Schools. 2014. "What Is Drill and Practice?" Available: http://olc.spsd.sk.ca/De/PD/instr/strats/drill/index.html. Last accessed March 3rd 2014.

[2] Wegerif, R. 2002. Report 2: Literature Review in Thinking Skills, Technology and Learning. Available: http://archive.futurelab.org.uk/resources/documents/lit_re views/Thinking_Skills_Review.pdf [2002]. Last accessed March 3rd 2014.

[3] Rouse, M. 2005. "Distance Learning." Available: http://whatis.techtarget.com/definition/distance-learninge-learning. Last accessed March 3rd 2014.

[4] Jain, P., Rao, D., and Bansal, V. 2014. "Ease of E-Learning for Special Needs Persons: Using E-Learning Utility." International Journal of Scientific and Research Publications: 4.

[5] Stevens, L. 2014. "History of Assistive Technology." Available:

http://www.timetoast.com/timelines/history-of-assistive-t echnology. Last accessed March 4rth 2014.

[6] Lankutis, T. 2004. "Special Needs Technologies: An Administrator's Guide." Technology \& Learning 25 (2): $30,32,34,36$.

[7] Thousand, J., and Villa, R. A. 2000. "Inclusion, Special Services in the Schools." 15: 73-108.

[8] Abbott, C. 2007. "E-inclusion: Learning Difficulties and Digital Technologies." REPORT 15: FUTURELAB SERIES. London, England.

[9] McDermott, P., and Watkins, M. 1983. "Computerized vs. Conventional Remedial Instruction for Learning Disabled Pupils." Journal of Special Education 17: 81-8.
[10] Boone, R., Higgins, K., and Notari, A. 1996. "Hypermedia Pre-reading Lessons: Learner Centered Software for Kindergarten." Journal of Computing in Childhood Education 7: 36-69.

[11] Higgins, E. L., and Raskind, M. H. 2000. "Speaking to Read: The Effects of continuous vs. Discrete Speech Recognition Systems of the Reading and Spelling of Children with Learning Disabilities." Journal of Special Education Technology 15: 19-30.

[12] Lewis, R. B., and Graves, A. W. 1998. "Word Processing Tools for students with Learning Disabilities: A Comparison of Strategies to Increase Text Entry Speed." Learning Disabilities Research \& Practice 13: 95-108.

[13] Lewis, R. B. 2000. "Musing on technology and Learning Disabilities on the Occasion of the New Millennium." Journal of Special Education Technology 15: 5-12.

[14] MacArthur, C. A. 2001. "Technology Implementation in Special Education." In Technology, Curriculum and Professional Development: Adapting Schools to Meet the Needs of Students with Disabilities, 115-20.

[15] Jeffs, T., and Morrison, W. F. 2014. "A Retrospective Analysis of Technological Advancements in Special Education." Available: http://edhd.bgsu.edu/ sbanist/portfolio/retro.htm. Last accessed March 3rd 2014.

[16] Daiute, C., and Morse, F. 1994. "Access to Knowledge and Expression: Multimedia Writing Tools for Students with Diverse Needs and Strengths." Journal of Special Education 12: 221-53.

[17] Press-Telegram. 2004. Learn about Disabled-Assistive Technology, Press-Telegram. California, USA.

[18] Lubinski, A. 2012. Technology Helps Instruct Developmentally Disabled. Washington, USA.

[19] Abramson, J. 1995. "Technology: Special Needs: Do-It-Yourself." Wall Street Journal. New York, USA.

[20] The Cairns Sun. 2012. New Technology Helps Special Needs Students. The Cairns Sun, Australia.

[21] Patrone, G., and Pettapiece, R. 2007. "Technology for Individuals with Special Needs." The Phi Delta Kappan [Online]. $88 . \quad$ Available: http://www.ldonline.org/article/6380/, last accessed March 3rd 2014.

[22] Quenneville, J. (n.d.). "Tech Tolls for Students with Learning Disabilities: Infusion into Inclusive Classrooms." LD Online [online]. Available: http://www.ldonline.org/article/6380/, last accessed March 3rd 2014.

[23] Alper, M., Hourcade, J. P., and Gilutz, S. 2012. "Interactive Technologies for children with Special Needs." In Proceedings of the 11th International Conference on Interaction Design and Children, 363-6. New York, USA. 
[24] Beukelman, D., and Mirenda, P. 1992. Augmentative and Alternative Communication: Management of Severe Communication Disorders in Children and Adults. Baltimore, USA.

[25] Angelo, D. H. 1995. "ACC in the family home." In Handbook of Augmentative and Alternative Communication, Singular, 523-41. San Diego, California, USA.

[26] Mann, W. C., and Lane, J. P. 1995. "Assistive Technology for Persons with Disabilities. The Role of Occupational Therapy." American Occupational Therapy Association. Rockville, MD, USA.

[27] Parette, H. P. 1997. "Assistive Technology Devices and Services." Education and Training in Mental Retardation and Developmental Disabilities 32: 267-80.

[28] Huntinger, P. L. 1996. "Computer Applications in Programs for Young Children with Disabilities: Recurring Themes." Focus on Autism and Other Developmental Disabilities 11: 105-14.

[29] Inge, K. J., and Shepherd, J. 1995. "Assistive Technology Applications and Strategies for School System Personnel." In Assistive Technology: A Resource for School, Work, and Community, 133-66. Baltimore, USA.

[30] Wehmeyer, M. L. 1998. "National Survey of the Use of Assistive Technology by Adults with Mental Retardation." Mental Retardation 36: 44-51.

[31] Denham, A., and. Lahm, E. A. 2001. "Using Technology to Construct Alternative Portfolios of Students with Moderate and Severe Disabilities." Teaching Exceptional Children 33: 10-7.

[32] Corbett, E. E., and Micheaux, P. A. 1996. "How Some Schools for Deaf and hard of Hearing Children Are Meeting the Challenges of Instructional Technology." American Annuals of the Deaf 141: 52-8.

[33] Stuckless, E. R. 1981. "Real-Time Graphic Display and Language Development for the Hearing Impaired." Volta Review 85: 291-300.

[34] Hairston, E. E. 1994. "Education Media Technology for Hearing-Impaired Persons: A Federal Perspective." American Annals of the Deaf 139: 10-3.

[35] Caldwell, D. C. 1981. "Closed-Captioned Television and the Hearing Impaired." Volta Review 83: 285-90.

[36] Wehmeyer, M. L. 1999. "Assistive Technology and Students with Mental Retardation: Utilization and Barriers." Journal of Special Education Technology 14: 48-58.

[37] Walker, P. 1991. "Where There Is a Way, There Is Not Always a Will: Technology, Public Policy, and the School Integration of Children Who Are Technology-Assisted." Children's Health Care 20: 68-74.

[38] Perlman, L. G. 1993. "The Views of Consumers with
Learning Disabilities, Mental Retardation and Their Caregivers." Electronic Industries Foundation.

[39] Spangenberg, L. 2005. "Accessible Technology for Disabled Students." The Chronicle of Higher Education 52: 0-A55.

[40] Williams, P. 2005. "Using Information and Communication Technology with Special Educational Needs Students: The Views of Frontline Professionals." Aslib Proceedings 57: 539-53.

[41] Okolo, C. M., and Kopke, R. A. 2013. "Disciplinary Literacy and Technology for Students with Learning Disabilities." Perspectives on Language and Literacy 39: 29-33.

[42] Courtad, C. A., and Bouck, E. C. 2013. "Learning Disabilities: Practice Concerns and Students with LD." Advances in Special Education 25: 153-74. (not in report)

[43] Reynolds, C. 2014. Federal Law 29-The Implications for Private Schools in the UAE, British Institute for Learning Development.

[44] Khaleej Times. 2014. "Dubai Law to Protect Rights of People with Special Needs." [Online] 14 March. Available at: http://www.khaleejtimes.com/nation/inside.asp?section=g overnment \&xfile=/data/government/2014/March/govern ment_March46.xml. [Accessed on 4th April 2014]

[45] Dyes, R. 2010. "Computers Help Special Needs People Become a Part of Mainstream Life.” [Online] 12 March. Available at: http://www.emirates247.com/eb247/companies-markets/t echnology/computers-help-special-needs-people-becomea-part-of-mainstream-life-2010-03-01-1.62700. [Accessed on 4th April, 2014]

[46] Moussly, R. 2012. "Centre for Special Needs Students Reaches Milestone." [Online] April 15. Available at: http://gulfnews.com/news/gulf/uae/education/centre-for-s pecial-needs-students-reaches-milestone-1.1008402. [Accessed on 4th April, 2014]

[47] Gaskell, H. 2014. "Samsung to Offer Educational Technology to Special Needs Children in UAE." [Online] 6 March. Available at: http://arabianindustry.com/technology/news/2014/mar/6/s amsung-to-offer-educational-technology-to-special-needs -children-4624360/\#.U0bQJPmSySp. [Accessed on 8th April, 2014]

[48] Sarby, S. 2014. "Autism Centre for Adults to Open in Dubai." [Online] 26 March. Available at: http://gulfnews.com/news/gulf/uae/general/autism-centrefor-adults-to-open-in-dubai-1.1309247. [Accessed on 19th April 2014]

[49] DubaiFAQs. 2014. "Special Needs Schools in the UAE." [Online] 14 February. Available at: http://www.dubaifaqs.com/schools-special-needs-uae.php. 
[Accessed on 4th April, 2014]

[50] UAE Interact. 2009. "SHEIKH MOHAMMED APPOINTS PRINCESS HAYA CHAIRWOMAN OF INDEMAJ." [Online] April 20. Available at: www.http://www.uaeinteract.com/docs/Sheikh_Mohamm ed_appoints_Princess_Haya_Chairwoman_of_INDEMAJ 135318.htm. [Accessed on 4th April, 2014]

[51] Emirates 24/7. 2010. "Indemaj Hosts Second Network Event." [Online] 28 November. Available at: http://www.emirates247.com/news/indemaj-hosts-second -network-event-2010-11-28-1.322431. [Accessed on 4th
April, 2014]

[52] Princess Haya Award for Special Education. 2009. [Online]. Available at: http://www.phase.ae/home.htm. [Accessed on 4th April, 2014]

[53] Anderson-Inman, L. 1991. "Enabling Students with Learning Disabilities: Insights from Research." Computer Teacher 18: 26-9.

[54] Morgan, R. L., and Gerity, B. P. 2000. "Using Video and CD-ROM Technology in a Job Preference Inventory for Youth with Severe Disabilities." Journal of Special Education Technology 15: 25-33. 